\title{
Enantioselective Chromatographic Analysis of Formoterol Fumarate using Chiral Mobile Phase Additives and Achiral Core-Shell Column
}

Pranav Pathak, Krishnapriya Mohanraj*

Department of Pharmaceutical Analysis, Bombay College of Pharmacy, Kalina, Santacruz (East), Mumbai- 400098, India

*Address for correspondence: Department of Pharmaceutical Analysis, Bombay College of Pharmacy, Kalina, Santacruz (East), Mumbai- 400098, India.

Email: krishnapriyamohanraj@bcp.edu.in 


\begin{abstract}
:
A simple, robust, cost-effective, and rapid RP-HPLC method was developed for the separation of enantiomers of formoterol. The separation was achieved by the chiral mobile phase additive technique on an achiral column. Formoterol is a bronchodilator that consists of 50:50 S, Sformoterol and R, R-formoterol. The bronchodilator activity is attributed to R, R-formoterol. Hence, it is important to develop a method to separate the enantiomers of formoterol. Various factors affecting enantiomeric resolution were investigated and optimized. The method was developed on core-shell Kinetex $\mathrm{C}_{8}$ column (150 mm x $4.6 \mathrm{~mm}$ I.D., $\left.5 \mu \mathrm{m}\right)$, using acetonitrile and $10 \mathrm{mM}$ sodium dihydrogen orthophosphate dihydrate buffer $\mathrm{pH} 3.0$ (adjusted with orthophosphoric acid) containing $5 \mathrm{mMS}-\beta-\mathrm{CD}$, in the composition of 10:90. The detection wavelength was set to $226 \mathrm{~nm}$, the mobile phase flow rate was $1 \mathrm{ml} / \mathrm{min}$, column temperature was set to $35^{\circ} \mathrm{C}$, and the injection volume was $20 \mu 1$. The enantiomers of formoterol were successfully separated with a resolution of 2.57 with a run-time of 9 minutes. The method was validated in accordance with ICH guidelines. The calibration curves were constructed for both enantiomers $\left(r^{2}=0.999\right)$ in the range of $2.5-25 \mu \mathrm{g} / \mathrm{ml}$. The repeatability and intermediate precision studies showed a relative standard deviation of less than $2 \%$. The limit of detection and limit of quantification was found to be 0.2 $\mu \mathrm{g} / \mathrm{ml}$ and $0.7 \mu \mathrm{g} / \mathrm{ml}$ respectively for both enantiomers. The $\%$ recovery for arformoterol was found to be between $99-101 \%$ and \% RSD was less than 2 . The validated method was successfully applied to the marketed formulation of arformoterol.
\end{abstract}

\title{
Keywords:
}

Enantioselective chromatography, Reversed phase-HPLC, Formoterol fumarate, Chiral mobile phase additive technique, Sulfated $\beta$-cyclodextrin, Core-shell silica column 


\section{Introduction:}

The significance of chirality is not unknown especially in the pharmaceutical industry where many of the therapeutic agents are chiral. Given the fact that the living systems are highly chiral, enantiomers of a given drug often display diverse biological responses. More often, active enantiomer (eutomer) produces the desired effects while another enantiomer (distomer) may be inactive or can produce undesired effects. ${ }^{1,2}$ After the tragic incidence of thalidomide in the $1960 \mathrm{~s}$, the regulators across the globe have made it necessary to consider racemic drug and each enantiomer to be a separate entity. Therefore, the properties of racemic drug and each enantiomer have to be thoroughly evaluated before commercializing the drug in any form. ${ }^{3}$

In response to the regulatory appeal, a sharp rise in the filings of single enantiomeric drugs was observed across the pharmaceutical industry. The role of enantioselective methods is very important at various stages of drug discovery and drug development. Chiral analytical methods are required for quality control of the drug substances and its products. It is important to separate and quantify the enantiomers of the drugs, during various stages of drug manufacturing and bioanalysis including pharmacokinetic, pharmacodynamic studies, and clinical trials of chiral drugs. ${ }^{1}$ As a result, there has been a remarkable impetus to develop new chiral chromatographic separation methods, on analytical and preparative scales.

Formoterol, ( \pm ) N-[2-hydroxy-5-[1-hydroxy-2-[1-(4-methoxyphenyl) propan-2-ylamino] ethyl] phenyl] formamide, is a long-acting beta-2 adrenoceptor agonist (LABA) which has significant bronchodilator effects. It is generally used to treat airways diseases, particularly asthma and exercise-induced bronchoconstriction (EIB). Formoterol is a chiral compound, which is generally administered as a 50:50 racemic mixture (via inhalation). The $(R, R)$-formoterol enantiomer produces the desirable pharmacological bronchodilator response, while $(S, S)$-formoterol is considered pharmacologically inactive (around 1000x less potent than the R-enantiomer). ${ }^{4,5,6}$ Handley et al. ${ }^{7}$ concluded that the therapeutic benefits of racemic formoterol can be attributed to $(\mathrm{R}, \mathrm{R})$-formoterol and $(\mathrm{S}, \mathrm{S})$ isomer is toxic. Hence, if $(\mathrm{R}, \mathrm{R})$-formoterol is used for the asthma treatment instead of racemic formoterol, adverse effects of (S, S)-formoterol can be eliminated. Hence, it is very important to separate the enantiomers of formoterol. The structure of formoterol is shown in Figure 1. 


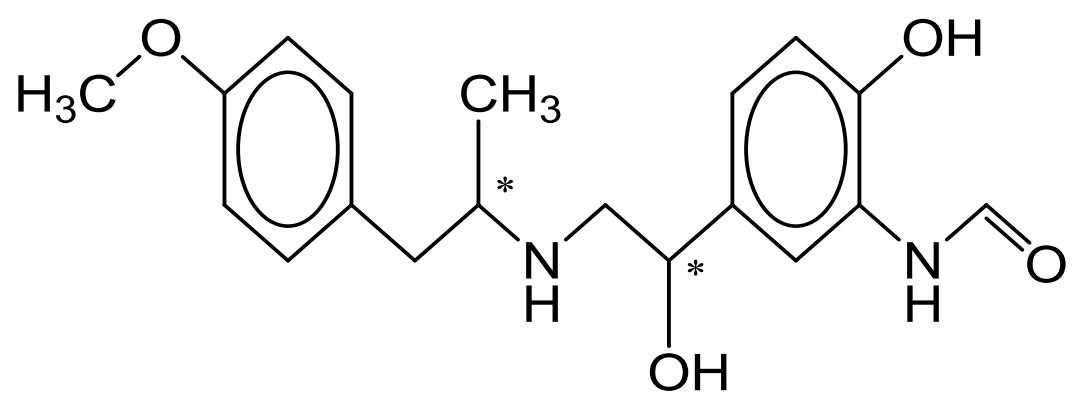

\section{Figure 1: Structure of formoterol}

Enantiomers have the same physicochemical properties except for rotation of the plane of polarized light and behavior in a chiral environment. In contrast, diastereomers have different physicochemical properties and can be separated relatively easily. Enantiomers of chiral drugs can be separated by HPLC using indirect and direct techniques. In both techniques, enantiomers are converted to diastereomers or diastereomeric complexes. The indirect technique employs chiral derivatizing agent and subsequent separation on an achiral column. In direct technique, a chiral selector is either on column (chiral stationary phase) or in the mobile phase (chiral mobile phase additive). The chiral mobile phase additives technique offers several advantages like low cost of separation attributed to the use of relatively inexpensive achiral stationary phases, absence of any derivatization step, and improved flexibility. Unlike chiral stationary phases, different chiral selectors can be investigated on a single achiral column. ${ }^{1,8,9}$

Cyclodextrin can form an inclusion complex with a wide variety of analytes. This makes them a popular chiral selector. Cyclodextrins form diastereomeric complexes with enantiomers that differ in their stability ${ }^{10,11}$. A survey of literature has indicated several reports stating the successful application of cyclodextrins and its derivatives as chiral mobile phase additives (CMPA). ${ }^{12-16}$ Our laboratory has also worked on enantioseparation of few APIs using CMPA. ${ }^{17,18,19}$

Previously, our research group has successfully separated enantiomers of milnacipran by CMPA technique, wherein sulfated $\beta$-cyclodextrin was added in the mobile phase as a chiral selector ${ }^{19}$. The core-shell silica column offered many benefits over the fully-porous silica column. The coreshell silica column helped not only in reducing analysis time without hindering enantiomeric resolution but also in reducing the overall consumption of chiral selector and solvents.

To the best of our knowledge, enantiomers of formoterol were not separated by $\beta$-cyclodextrins in CMPA mode. Butter, et al. ${ }^{20}$ reported the separation of enantiomers of formoterol using the chiral stationary phase chiral $\alpha 1$ - acid glycoprotein (AGP) column and electrochemical detection. 
Akapo, et al. ${ }^{21}$ reported chiral HPL C analysis of formoterol stereoisomers using Chiral-AGP column.

Hence, it was decided to develop a chromatographic method for the separation of enantiomers of formoterol using $\beta$-cyclodextrins and its derivatives as chiral mobile phase additives and achiral column i.e. excluding the use of costly chiral columns.

\section{MATERIALS AND METHODS}

\section{Chemicals and reagents}

Racemic formoterol fumarate and arformoterol tartrate were obtained as gift samples from Cipla Ltd, Mumbai, India. Sodium dihydrogen orthophosphate dihydrate (HPLC grade) and orthophosphoric acid (AR grade) were purchased from S.D. Fine Chem Pvt. Ltd, Mumbai, India. Methanol and acetonitrile (HPLC grade) were purchased from Merck Chem Ltd., Mumbai, India. Chiral mobile phase additives such as $\beta$-cyclodextrin $(\beta-\mathrm{CD})$ and hydroxypropyl $\beta$-cyclodextrin $(\mathrm{Hp}-\beta-\mathrm{CD})$ were gift samples from Signet Chemical Corporation, Mumbai, India. Sulfated $\beta$ cyclodextrin (S- $\beta-\mathrm{CD}$ ) was synthesized in-house (Manuscript under review). Arformoterol tartrate respsules (Labaneb, $15 \mu \mathrm{g} / 2 \mathrm{ml}$ ) manufactured by Lupin Pharmaceuticals, purchased from the open market were used for assay studies.

\section{Instrumentation and chromatographic conditions}

The HPLC system used was Agilent Infinity 1260 II, which consisted of a quaternary HPLC pump, auto-sampler, column oven, and diode array detector. Data acquisition and processing were performed using EZChrome software. The chromatographic columns used during method development were Kinetex $\mathrm{C}_{8}(150 \mathrm{~mm}$ x $4.6 \mathrm{~mm}$ I.D., $5 \mu \mathrm{m} \& 2.6 \mu \mathrm{m})$ and Hyperclone $\mathrm{C}_{8}(150$ $\mathrm{mm} \times 4.6 \mathrm{~mm}$ I.D., $5 \mu \mathrm{m}$ ). The flow rate of the mobile phase was $1.0 \mathrm{ml} / \mathrm{minute}$ and the column temperature was maintained at $35^{\circ} \mathrm{C}$. The eluent was monitored at a wavelength of $226 \mathrm{~nm}$. The injection volume was $20 \mu 1$.

\section{Preparation of the mobile phase}

Acetonitrile and 10mM sodium dihydrogen orthophosphate dihydrate buffer $\mathrm{pH} 3.0$ (adjusted with orthophosphoric acid) containing CMPA were used as mobile phase components. The buffer was filtered through a $0.45 \mu \mathrm{m}$ durapore nylon filter and sonicated for 5 minutes before use. 


\section{Preparation of sample solution}

Stock solutions of racemic formoterol fumarate and arformoterol tartrate were prepared by dissolving $20 \mathrm{mg}$ of each drug in $20 \mathrm{ml}$ methanol separately. The preparation of the working standard solutions included suitable dilutions of primary stock solution with the mobile phase.

The process map for the enantiomeric separation of formoterol is shown in Figure 2.

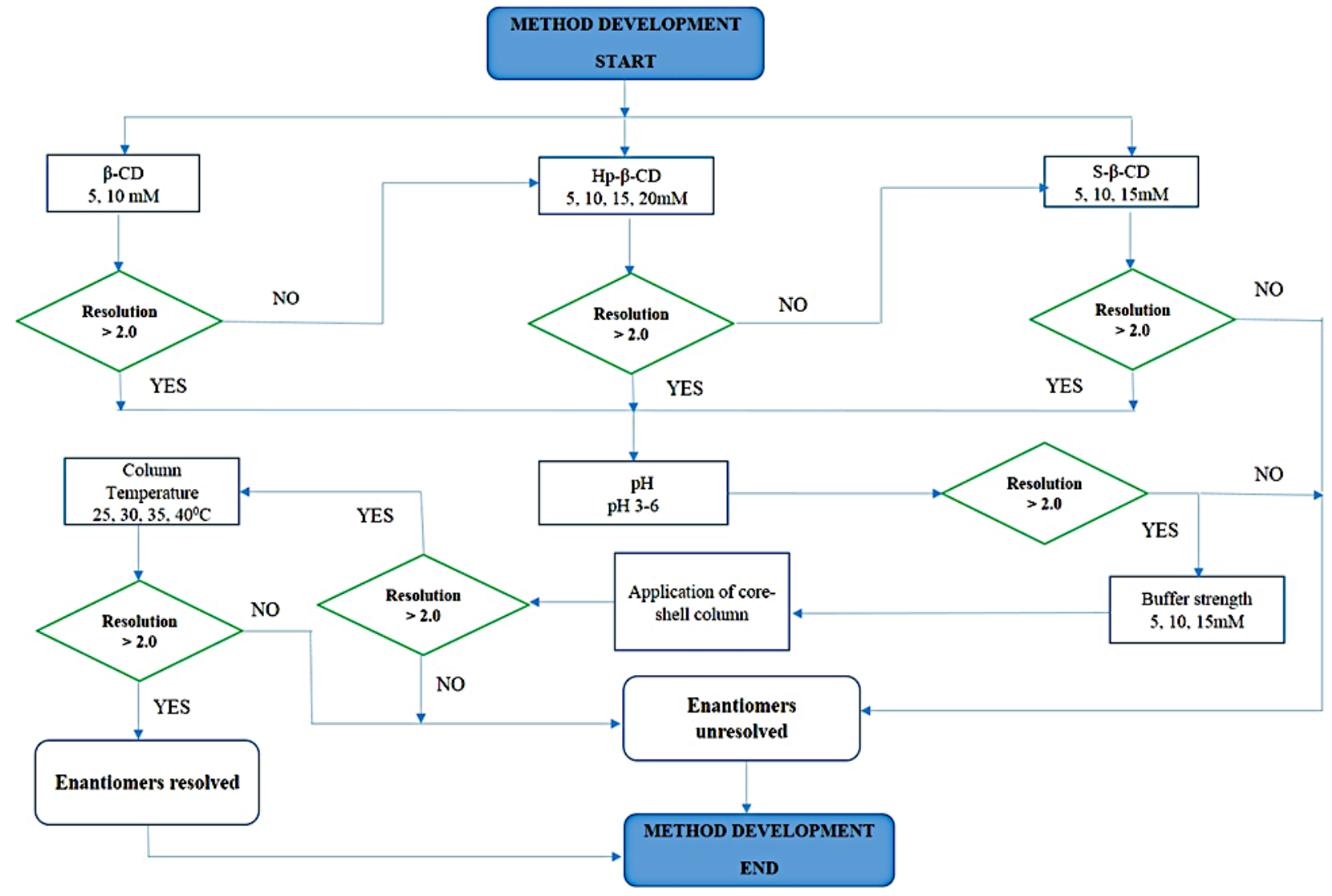

Figure 2: Process map for enantiomeric separation of formoterol

\section{Chiral HPLC Method development}

For HPLC method development, $20 \mu \mathrm{g} / \mathrm{ml}$ of racemic formoterol was injected $(20 \mu \mathrm{l})$. To achieve the best separation between the enantiomers, various parameters affecting resolution were evaluated.

\section{Effect of type and concentration of $\beta$-cyclodextrins:}

5 and $10 \mathrm{mM} \beta-\mathrm{CD} ; 5,10,15$, and $20 \mathrm{mM} \mathrm{Hp}-\beta-\mathrm{CD}$; and 5 and $10 \mathrm{mM} \mathrm{S}-\beta-\mathrm{CD}$ were the concentrations of CMPA evaluated. The results of method development using the Hyperclone C8 column are mentioned in Table 1. 
Table 1: HPLC method development using Hyperclone C8 column

\begin{tabular}{|c|c|c|c|c|}
\hline Sr. No. & CMPA & ACN: Buffer & Retention time (minutes) & Resolution \\
\hline 1 & No CMPA & $10: 90$ & 36.61 & - \\
\hline 2 & $5 \mathrm{mM} \beta-\mathrm{CD}$ & $10: 90$ & 32.1 & - \\
\hline 3 & $10 \mathrm{mM} \beta-\mathrm{CD}$ & $10: 90$ & 26.36 & - \\
\hline 4 & 5mM Hp- $\beta-C D$ & $10: 90$ & 29.6 & 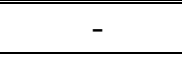 \\
\hline 5 & $10 \mathrm{mM}$ Hp- $\beta-\mathrm{CD}$ & $10: 90$ & 22.6 & - \\
\hline 6 & $15 \mathrm{mM}$ Hр- $\beta$-CD & $10: 90$ & 21.63 & - \\
\hline 7 & 20mM Hp- $\beta-C D$ & $10: 90$ & 19.47 & - \\
\hline \multirow[t]{3}{*}{8} & \multirow[t]{3}{*}{$5 \mathrm{mM} S-\beta-\mathrm{CD}$} & $20: 80$ & $3.4 \& 3.6$ & 1.11 \\
\hline & & $15: 85$ & $5.7 \& 6.4$ & 1.86 \\
\hline & & $10: 90$ & $12.4 \& 14.9$ & 3.11 \\
\hline 9 & $10 \mathrm{mM} \mathrm{S}-\beta-\mathrm{CD}$ & $10: 90$ & $10.9 \& 13.8$ & 3.22 \\
\hline 10 & $15 \mathrm{mM}$ S- $\beta-\mathrm{CD}$ & $10: 90$ & $9.96 \& 12$ & 3.16 \\
\hline
\end{tabular}

Mobile phase: Acetonitrile: $10 \mathrm{mM}$ sodium dihydrogen orthophosphate dihydrate buffer containing CMPA pH 3.0 adjusted with orthophosphoric acid, Column: Hyperclone C8 $(150 x 4.6 \mathrm{~mm}, 5 \mu \mathrm{m})$, Flow rate: $1 \mathrm{ml} / \mathrm{min}$, Detection wavelength: $226 \mathrm{~nm}$, Column temperature: $25^{\circ} \mathrm{C}$

The method development was started using the Hyperclone C8 column without adding any CMPA in the mobile phase. The retention time was 36.61 minutes with $10 \%$ acetonitrile in the mobile phase. When $\beta-C D$ was added in the mobile phase, the retention time decreased to 32.1 and 26.36 minutes with 5 and $10 \mathrm{mM} \beta-\mathrm{CD}$ in the mobile phase respectively. However, no resolution was obtained with $\beta-C D$ as CMPA. When Hp- $\beta-C D$ was added in the mobile phase, with increment in the concentration of $\mathrm{Hp}-\beta-\mathrm{CD}$, the retention times decreased without any resolution. The reduction in retention time with increment in the concentration of CMPA can be attributed to the formation of the inclusion complex between CMPA and analyte, which increases the polarity of the analyte, thereby reducing the residing time of analyte on a reversed-phase HPLC column.

With $5 \mathrm{mM}$ S- $\beta$-CD some resolution (1.11) was obtained when $20 \%$ acetonitrile was used as the organic component in the mobile phase. On the reduction of acetonitrile in the mobile phase, a very good resolution of 3.11 was obtained with $10 \%$ acetonitrile. For optimization of the concentration of S- $\beta$-CD. 5, 10, and $15 \mathrm{mM}$ S- $\beta$-CD were selected. The effect of concentration of $\mathrm{S}-\beta-\mathrm{CD}$ on retention time and resolution is shown in Figure 3. (SFM= S-formoterol, $\mathrm{RFM}=\mathrm{R}-$ formoterol) 


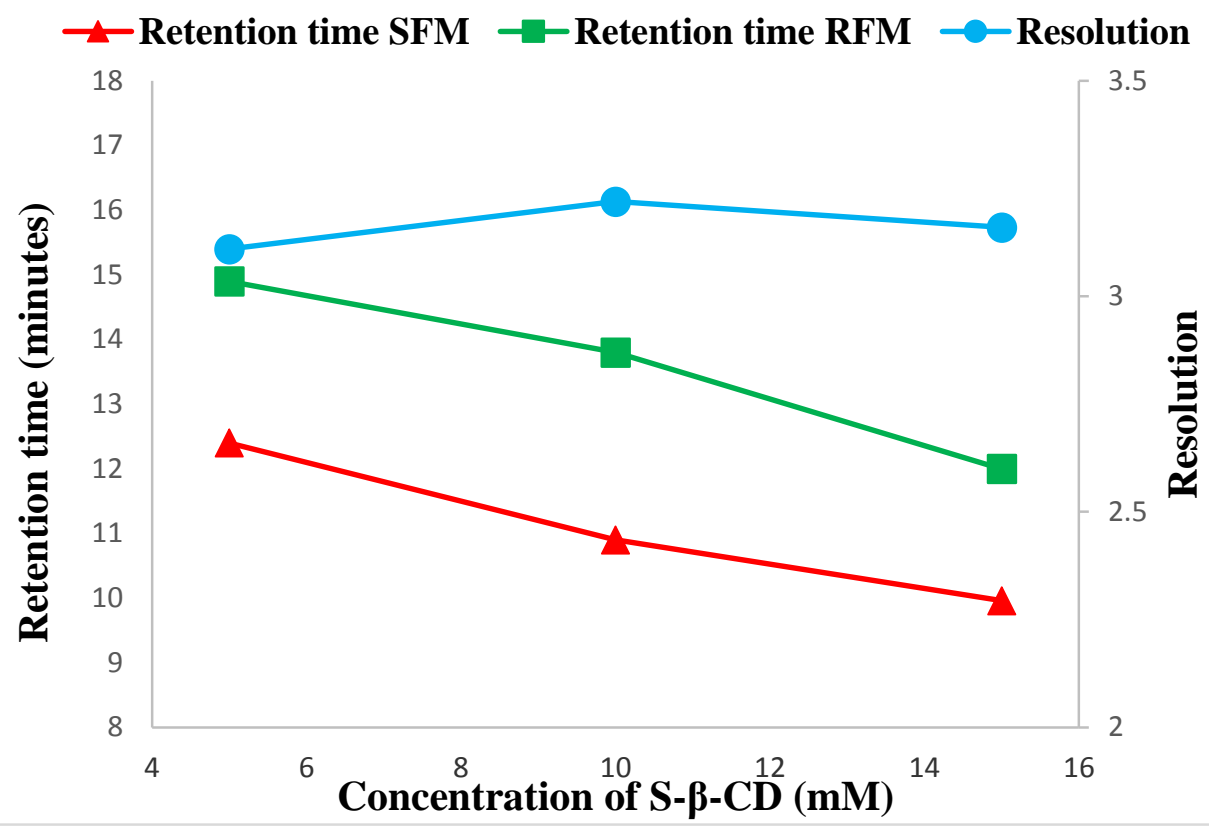

Mobile phase: Acetonitrile: $5 \mathrm{mM}$ sodium dihydrogen orthophosphate dihydrate buffer CMPA pH 3.0 adjusted with

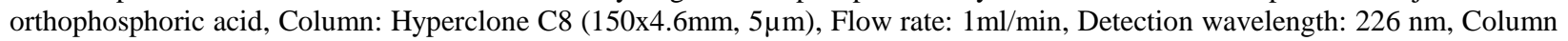
temperature: $25^{\circ} \mathrm{C}$

\section{Figure 3: Effect of concentration of $S-\beta-C D$ on retention time and resolution}

A clear pattern is observed. As the concentration of $S-\beta-C D$ was increased, the retention times decreased. A fairly good resolution was obtained with 5, 10, and 15mM S- $\beta$-CD. 5mM S- $\beta$-CD was selected as an optimum concentration. In 5, 10, and $15 \mathrm{mM} \mathrm{S- \beta -CD} \mathrm{concentrations,} \mathrm{resolution}$ between enantiomers was above 3 . The major difference was in retention times. Though retention times were comparatively high with $5 \mathrm{mM}$ S- $\beta-\mathrm{CD}$, the total consumption of S- $\beta$-CD was relatively low. With a higher concentration of any CMPA, more often higher back-pressure was obtained that leads to reduced column life-time. Hence, $5 \mathrm{mM}$ S- $\beta$-CD was selected.

It is important to note that enantiomers of formoterol were not separated when $\beta-\mathrm{CD}$ and Hp- $\beta$ CD were employed as CMPA. At $\mathrm{pH} 3.0, \beta-\mathrm{CD}$ and $\mathrm{Hp}-\beta-\mathrm{CD}$ exists in neutral form, whereas $\mathrm{S}$ $\beta-C D$ exists in anionic form. It can be postulated that the negatively charged sulfonic acid group favors interaction with a positively charged group on the analyte and thus imparts stability to the inclusion complex which is essential for the separation of enantiomers.

\section{Effect of pH:}

In order to study the effect of $\mathrm{pH}$, four $\mathrm{pHs}(3,4,5$, and 6) were selected. At $\mathrm{pH} 3.0$, the best resolution was obtained. The effect of $\mathrm{pH}$ on retention time and resolution is shown in Figure 4. 


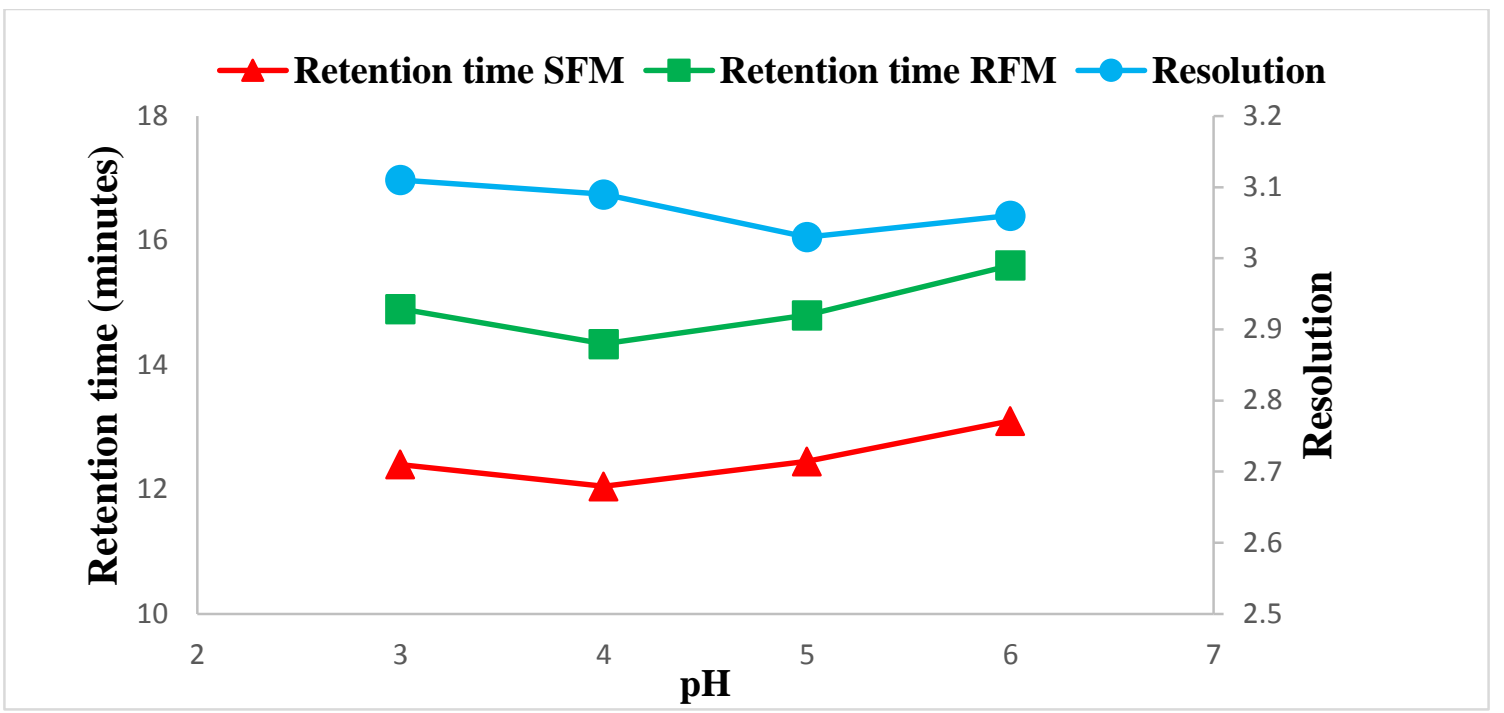

Chromatographic conditions: Mobile phase: Acetonitrile: $5 \mathrm{mM}$ sodium dihydrogen orthophosphate dihydrate buffer $5 \mathrm{mM} \mathrm{S-} \beta$-CD $\mathrm{pH}(3,4,5,6)$ adjusted with orthophosphoric acid (10:90), Column: Hyperclone C8 (150x4.6mm, $5 \mu \mathrm{m})$, Flow rate: $1 \mathrm{ml} / \mathrm{min}$, Detection wavelength: $226 \mathrm{~nm}$, Column temperature: $25^{\circ} \mathrm{C}$

\section{Figure 4: Effect of pH on retention time and resolution}

As shown in Figure 3, a decrease in $\mathrm{pH}$ leads to better resolution with little decrease in retention times. Formoterol is a basic drug (pKa 9.81) and in acidic $\mathrm{pH}$ it mainly exists in cationic form. S$\beta-\mathrm{CD}$, due to the presence of strongly acidic sulfonic acid groups is expected to be present in the anionic form. This ensures multipoint interactions between S- $\beta-C D$ and the enantiomers leading to higher chiral recognition. It is observed that the best separation is obtained when the $\mathrm{pH}$ of the mobile phase is kept 3. Although the retention times are nearly the same for $\mathrm{pH} 3,4,5$, and 6 , the resolution is best $(\mathrm{Rs}=3.11)$ at $\mathrm{pH} 3$.

\section{Effect of buffer strength:}

To investigate the effect of buffer strength i.e. the concentration of buffer in the mobile phase, experiments were designed with 5,10 , and $15 \mathrm{mM}$ buffer in the aqueous phase. $5 \mathrm{mM}$ buffer was selected since the retention times are lower and resolution is best.

\section{Effect of an achiral core-shell column:}

In order to check the effect of achiral core-shell column, the same chromatographic conditions

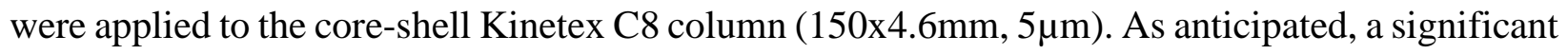
reduction in retention time was observed without impeding resolution. The resolution was reduced to 2.59 with the run-time of 9 minutes. The comparison of two types of the achiral column is shown in Table 2. 
Table 2: Comparison of two types of achiral column

\begin{tabular}{|c|c|c|c|}
\hline Column type & Achiral column & $\begin{array}{c}\text { Retention times } \\
\text { (minutes) }\end{array}$ & Resolution \\
\hline Fully porous silica & Hyperclone C8 & $11.4 \& 13.8$ & 3.14 \\
\hline Core-shell silica & Kinetex C8 & $6.15 \& 7.61$ & 2.59 \\
\hline
\end{tabular}

Chromatographic conditions: Mobile phase: Acetonitrile: 5, 10, 15mM sodium dihydrogen orthophosphate dihydrate buffer 5mM $\mathrm{S}-\beta-\mathrm{CD} \mathrm{pH} 3$ adjusted with orthophosphoric acid (10:90), Flow rate: $1 \mathrm{ml} / \mathrm{min}$, Detection wavelength: $226 \mathrm{~nm}$, Column temperature: $25^{\circ} \mathrm{C}$

\section{Effect of column temperature:}

Column temperatures under the investigation were $25,30,35$, and $40^{\circ} \mathrm{C}$. The effect of column temperature on retention time and resolution is shown in Figure 5.

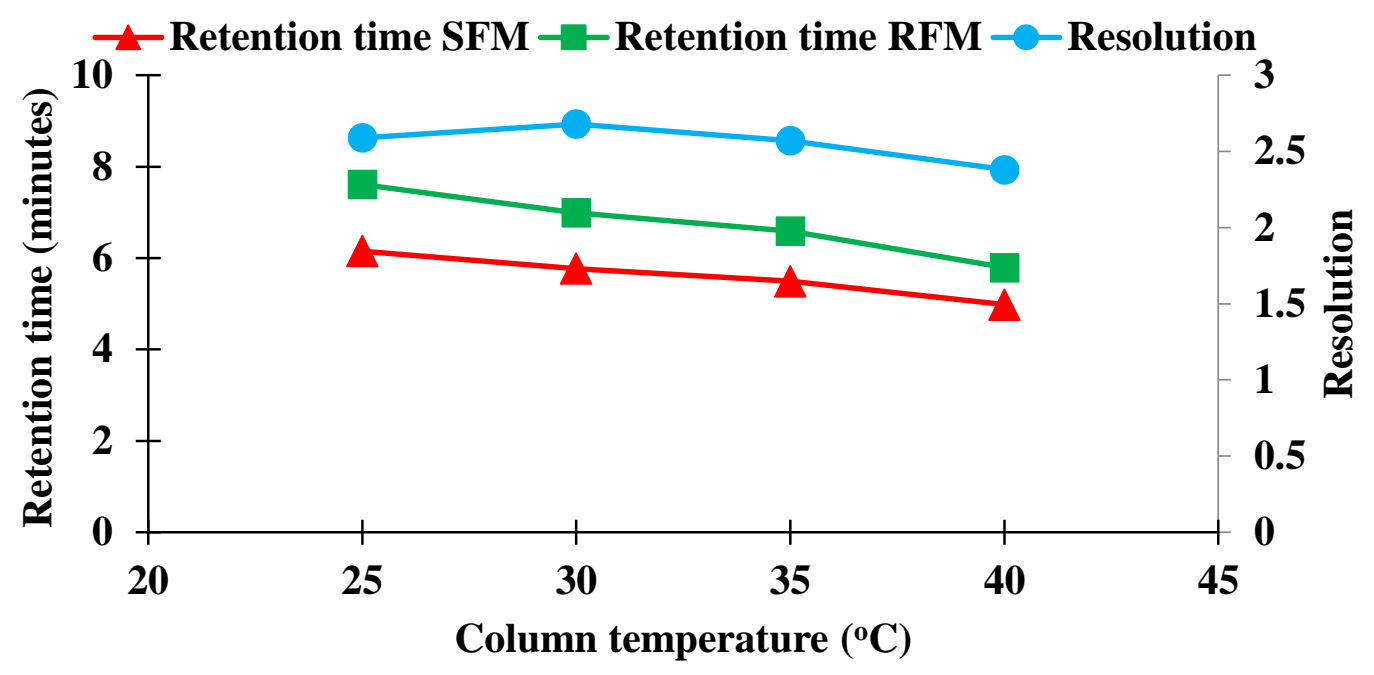

Figure 5: Effect of column temperature on retention time and resolution

From the above results, it was observed that as temperature increased, the retention time decreased, and resolution also plunged down a little, but it was within acceptable levels. When column temperature was $40^{\circ} \mathrm{C}$, resolution (2.38) and retention times were lowest amongst all and the plate count (3867 \& 4173) was higher. The next choice was $35^{\circ} \mathrm{C}$. At this temperature retention times were lower than $25^{\circ} \mathrm{C}$ and $30^{\circ} \mathrm{C}$ with good resolution of 2.57 and good plate count $(3207 \& 3563)$. Hence, $35^{\circ} \mathrm{C}$ was selected for method validation. The final developed method is given in Table 3 .

Table 3: The final developed method

\begin{tabular}{|c|c|c|c|c|}
\hline Column & Mobile phase & $\begin{array}{l}\text { Flow } \\
\text { rate }\end{array}$ & $\begin{array}{c}\text { Detection } \\
\text { wavelength }\end{array}$ & $\begin{array}{c}\text { Column } \\
\text { temperature }\end{array}$ \\
\hline $\begin{array}{c}\text { Kinetex C8 } \\
(150 x 4.6 \mathrm{~mm}, \\
5 \mu \mathrm{m})\end{array}$ & $\begin{array}{c}\text { Acetonitrile: } 5 \mathrm{mM} \text { sodium } \\
\text { dihydrogen orthophosphate } \\
\text { dihydrate buffer } 5 \mathrm{mM} \text { S- } \beta \text {-CD pH } \\
3.00(10: 90)\end{array}$ & $1 \mathrm{ml} / \mathrm{min}$ & $226 \mathrm{~nm}$ & $35^{\circ} \mathrm{C}$ \\
\hline
\end{tabular}


The representative chromatogram is shown in Figure 6.

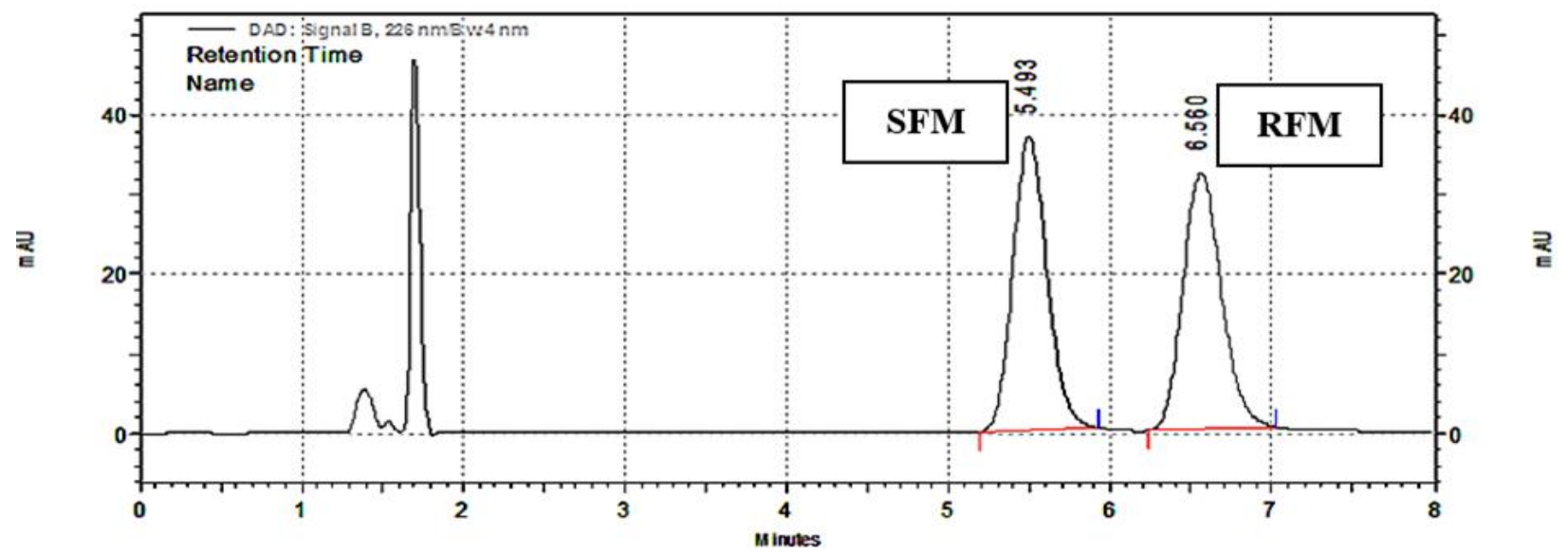

Chromatographic conditions: Mobile phase: Acetonitrile: $5 \mathrm{mM}$ sodium dihydrogen orthophosphate dihydrate buffer $5 \mathrm{mM}$ S- $\beta$-CD

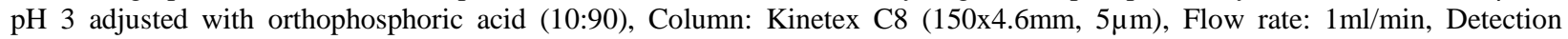
wavelength: $226 \mathrm{~nm}$, Column temperature: $35^{\circ} \mathrm{C}$

Figure 6: The representative chromatogram of separation of enantiomers of formoterol

The system suitability parameters for a final developed method are mentioned in Table 4.

Table 4: System Suitability Parameters

\begin{tabular}{|c|c|c|c|c|}
\hline Enantiomer & $\begin{array}{c}\text { Retention Time } \\
\text { (minutes) }\end{array}$ & Resolution & $\begin{array}{c}\text { Asymmetry } \\
\text { factor }\end{array}$ & $\begin{array}{c}\text { Number of } \\
\text { theoretical plates }\end{array}$ \\
\hline SFM & 5.49 & - & 1.15 & 3207 \\
\hline RFM & 6.56 & 2.57 & 1.15 & 3563 \\
\hline
\end{tabular}

\section{Method validation}

After optimization of the parameters affecting the enantiomeric separation of formoterol, the method was validated for linearity, the limit of detection (LOD), the limit of quantification (LOQ), precision, accuracy, and robustness as per ICH guidelines on both the columns.

\section{Specificity:}

Specificity study was conducted to check the interference of any other peak at the retention time of the enantiomers peak in blank solution. Diluent was injected as a blank solution. Both peaks are well separated and no interference from blank was observed. All system suitability parameters are as per norms. The system suitability parameters are mentioned in Table 4.

\section{Linearity}

To determine the linearity, $5-50 \mu \mathrm{g} / \mathrm{ml}$ of racemic formoterol was injected (20 $\mu \mathrm{l}) 3$ times, and the calibration curve was constructed by plotting peak areas versus analyte concentration for both enantiomers in the range of $2.5-25 \mu \mathrm{g} / \mathrm{ml}$. From the plot, the slope, $\mathrm{y}$-intercept, and correlation 
coefficient $\left(\mathrm{r}^{2}\right)$ were determined. The linearity equation for SFM was $\mathrm{y}=111462 \mathrm{x}-9013.9$ and for RFM was $y=109890 x-6379.4$. Good correlation coefficients $\left(r^{2}\right), 0.9995$ and 0.9993 were obtained for SFM and RFM respectively.

\section{Precision}

The precision of the method was performed by repeatability and intermediate precision studies. The repeatability of the method was determined by making 3 injections at three different concentration levels $(10,20$, and $30 \mu \mathrm{g} / \mathrm{ml})$ of racemic formoterol and $\%$ RSD for each enantiomer was less than 2. The intermediate precision of the method was calculated by intra-day precision and inter-day precision studies. For intermediate precision, racemic formoterol was injected six times twice in a day and on a different day. \% RSD was calculated for the replicate injections in repeatability and intermediate precision and was found to be less than $2 \%$ for both enantiomers.

\section{Accuracy}

The accuracy of the method was measured by conducting recovery studies by spiking Rformoterol. Recovery studies for R-formoterol were conducted at three concentration levels i.e. at $50 \%(5 \mu \mathrm{g} / \mathrm{ml}), 100 \%(10 \mu \mathrm{g} / \mathrm{ml})$ and $150 \%(15 \mu \mathrm{g} / \mathrm{ml})$ of target concentration $(10 \mu \mathrm{g} / \mathrm{ml})$. Each concentration level was analyzed in triplicate and \% recovery was calculated. The \% recovery for arformoterol was found to be between $99-101 \%$ and \% RSD was less than $2 \%$.

\section{Limit of detection and quantification}

To determine LOD and LOQ, series of dilute solutions were injected in triplicate. LOD and LOQ were calculated on the basis of the response and slope of the regression equation. They were calculated from the formula $3.3 \sigma / \mathrm{s}$ and $10 \sigma / \mathrm{s}$ respectively. The limit of detection and limit of quantification was found to be $0.2 \mu \mathrm{g} / \mathrm{ml}$ and $0.7 \mu \mathrm{g} / \mathrm{ml}$ respectively for both enantiomers.

\section{Robustness}

To determine the robustness of the method, deliberate changes were made in the experimental conditions of the developed method. The resolution between two enantiomers and system suitability parameters were evaluated. The variables evaluated in the study were flow rate $( \pm 0.1$ $\mathrm{ml} / \mathrm{min}$.), $\mathrm{pH}$ of mobile phase ( \pm 0.2 units), mobile phase composition ( \pm 2 units) and variation in detection wavelength $( \pm 2 \mathrm{~nm})$. Robustness was determined from triplicate injections of racemic formoterol. In all cases, the resolution was greater than 2.0, \% RSD of peak area was less than 2 and the asymmetry factor was less than 1.5 for both the enantiomers. 


\section{HPLC analysis for assay of arformoterol (RFM) in Labaneb respules}

The validated method was then applied to determine the content of arformoterol (RFM) in Labaneb respules. $7.5 \mu \mathrm{g} / \mathrm{ml}$ arformoterol was injected in triplicate and \% RSD was less than 2 . The sample of labaneb respules was found to contain $102.4 \%$ of the stated amount arformoterol. The representative chromatogram of arformoterol in the formulation is shown in Figure 7.

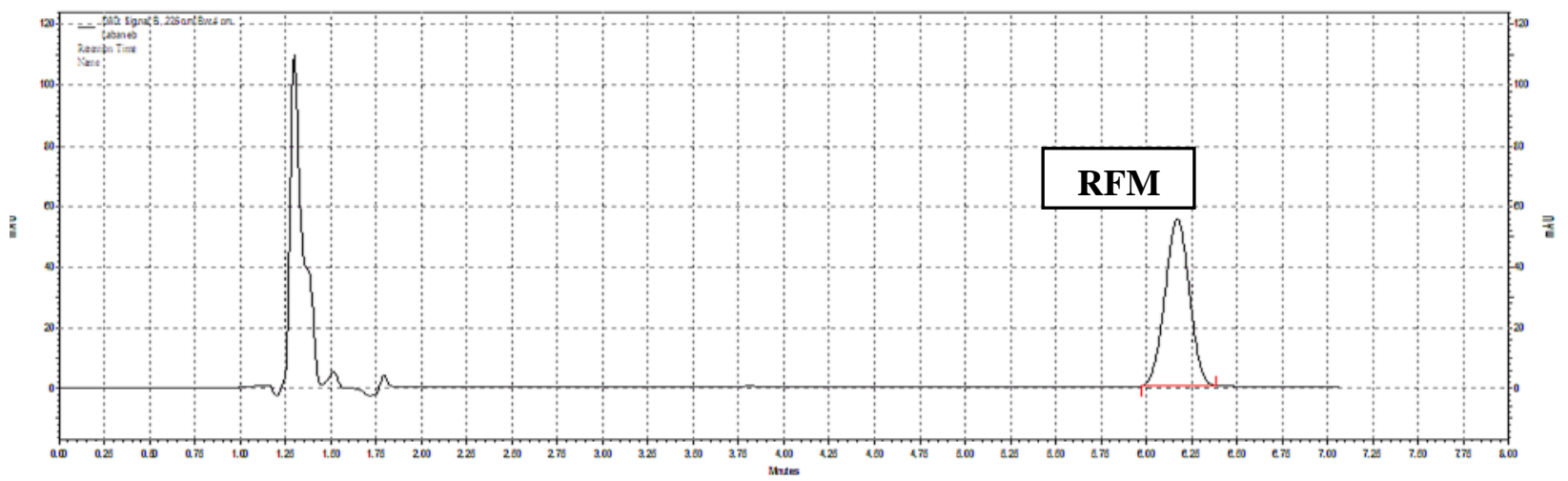

Figure 7: Assay of arformoterol tartrate formulation

\section{Effect of particle size of the column:}

The Kinetex C8 column (150x4.6mm, $5 \mu \mathrm{m}$ ) on which the method for enantiomeric separation of formoterol was developed, validated, and applied to marketed formulation was quite old. When new Kinetex C8 (150x4.6mm) was used with the smaller particle size of $2.6 \mu \mathrm{m}$ excellent results were obtained. The retention-times decreased, there was a significant improvement in resolution, asymmetry factor, and the number of theoretical plates was improved. The chromatogram is shown in Figure 8.

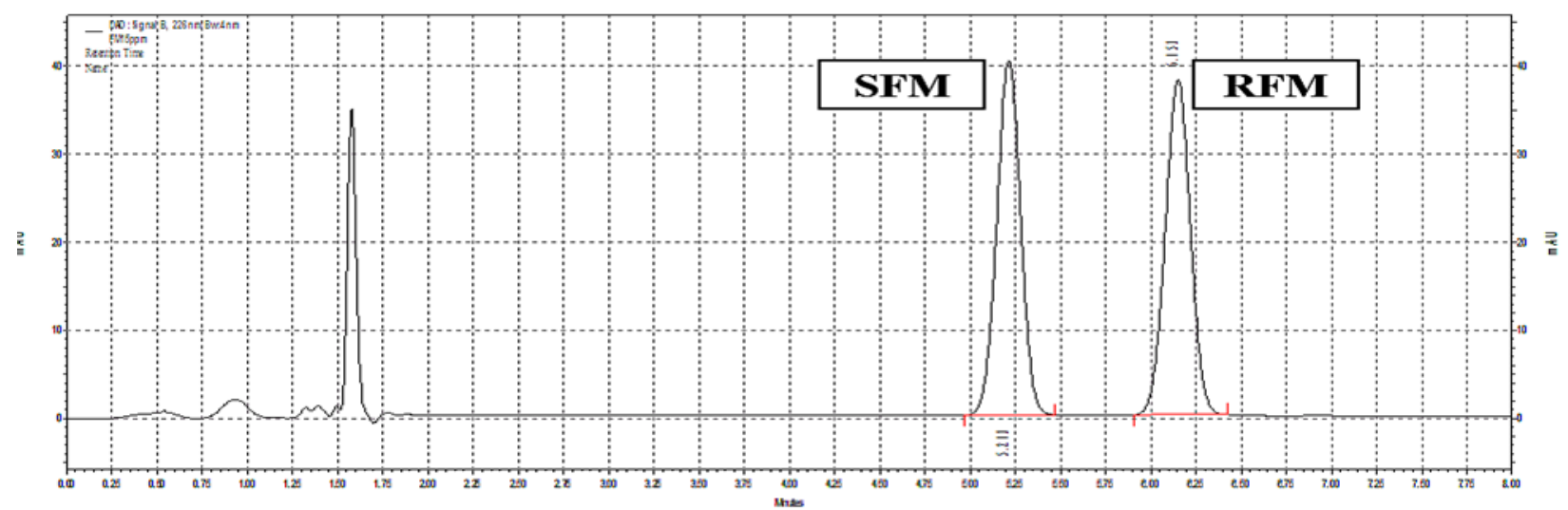

Chromatographic conditions: Mobile phase: Acetonitrile: $5 \mathrm{mM}$ sodium dihydrogen orthophosphate dihydrate buffer $5 \mathrm{mM}$ S- $\beta$-CD pH 3 adjusted with orthophosphoric acid (10:90), Column: Kinetex C8 (150x4.6mm, 2.6 $\mu \mathrm{m})$, Flow rate: 1ml/min, Detection wavelength: $226 \mathrm{~nm}$, Column temperature: $35^{\circ} \mathrm{C}$

Figure 8: The representative chromatogram of separation of enantiomers of formoterol 
The system suitability parameters are mentioned in Table 5.

Table 5: System Suitability Parameters

\begin{tabular}{|c|c|c|c|c|}
\hline Enantiomer & $\begin{array}{c}\text { Retention Time } \\
\text { (minutes) }\end{array}$ & Resolution & $\begin{array}{c}\text { Asymmetry } \\
\text { factor }\end{array}$ & $\begin{array}{c}\text { Number of } \\
\text { theoretical } \\
\text { plates }\end{array}$ \\
\hline SFM & 5.21 & - & 1.01 & 7179 \\
\hline RFM & 6.15 & 3.71 & 0.99 & 8925 \\
\hline
\end{tabular}

\section{Conclusion}

A simple, cost-effective, and rapid RP-HPLC method for the separation of enantiomers of formoterol was developed and validated. The simplicity and cost-effectiveness of the method can be credited to the fact that S- $\beta-C D$ was employed as a chiral mobile phase additive. Separation of enantiomers was achieved on relatively inexpensive achiral columns, by-passing the derivatization step and excluding the use of the costly chiral column. The factors affecting resolution between enantiomers were optimized. The key step in achieving successful separation of enantiomers was the formation of stable inclusion complex between enantiomer and S- $\beta$-CD and subsequent separation on the achiral column due to the difference in the stability of inclusion complexes. With the help of the core-shell silica column (Kinetex C8), the method was quite quick with reduced analysis time, consumption of chiral selector, and solvents. The validated method was successfully applied to a pharmaceutical formulation of arformoterol. However, there is a scope for work to elucidate chiral recognition mechanism using computational techniques.

\section{Acknowledgments}

The authors are thankful to the Department of Science and Technology (DST-DPRP: Project sanction number: VI-D\&P/552/2016-17/TDT (G) dated 07.03.2017), New Delhi for funding this project. We are also thankful to Cipla Ltd (Mumbai, India) for providing racemic formoterol fumarate and arformoterol tartrate. Further, the authors wish to acknowledge Signet Chemicals (Mumbai, India) for providing $\beta$-cyclodextrin and hydroxypropyl- $\beta$ - cyclodextrin.

\section{References:}

1. S. Ahuja, Chiral separations by liquid chromatography, American Chemical Society, 1991.

2. C. Brown C, Chirality in drug design and synthesis, Academic Press, 2013 Oct 22.

3. J. Tomaszewski J, and M. M. Rumore, Drug Dev. Ind. Pharm.,1994, 20(2), 119-139. 
4. D. Schmidt, B. L. Källström, B. Waldeck, D. Branscheid , H. Magnussen , and K. F. Rabe, Naunyn-Schmiedeberg's Arch. Pharmacol., 2000, 361(4), 405-409.

5. G. A. Jacobson, M. Hostrup, C. K. Narkowicz, D. S. Nichols, and E. H. Walters, Drug Test. Anal., 2019, 11(7), 950-956.

6. B. L. Källström, J. Sjöberg, and B. Waldeck, Chirality, 1996, 8(8), 567-573.

7. D. A. Handley, C. H. Senanayake, W. Dutczak, J. L. Benovic, T. Walle, R. B. Penn, H. S. Wilkinson, G. J. Tanoury, R. G. Andersson, F. Johansson, and J. Morley J, Pulm. Pharmacol. Ther., 2002, 15(2), 135-145.

8. N. M. Maier, P. Franco, and W. Lindner, J. Chromatogr. A., 2001, 906(1-2), 3-33.

9. G. K. Scriba, Chiral separations: methods and protocols, New York, Humana Press; 2013.

10. W. J. Lough, Chiral liquid chromatography, Glasgow, Blackie; 1989.

11. H. Y. Aboul-Enein, and I. Ali, Chiral separations by liquid chromatography and related technologies, CRC Press, 2003.

12. J. Xie, Q. Tan, L. Yang, S. Lai, S. Tang, C. Cai, and X. Chen, Anal. Methods., 2014, 6(12), 4408-4413.

13. R. Herráez-Hernández, and P. Campíns-Falcó, J. Chromatogr. B: Biomed. Sci. Appl., 2000, 740(2), 169-177.

14. S. D. Sharma, and G. Singh, Adv. Anal. Chem., 2012, 2(4), 25-31.

15. S. Ma, S. Shen, N. Haddad, W. Tang, J. Wang, H. Lee, N. Yee, C. Senanayake, and N. Grinberg, J. Chromatogr. A., 2009, 1216(8), 1232-1240.

16. D. Chen, S. Jiang, Y. Chen, Y. Hu, J. Pharm. Biomed. Anal., 2004, 34(1), 239-45.

17. KR Deshpande, MA Pillai, V Joshi, KR Mohanraj, Int. J. Pharm. Pharm. Sci., 2015, 7(6), 30610.

18. K. Deshpande; P. Pathak; V. Joshi; S. Barton, and K.Mohanraj, ChemRxiv, 2020, preprint, DOI: https://doi.org/10.26434/chemrxiv.11907060.v1

19. P. Pathak, V. Jain, E. Martis, E. C. Coutinho, and K. Mohanraj, ChemRxiv, 2020, preprint. DOI: https://doi.org/10.26434/chemrxiv.11726196.v2

20. J. J. Butter, B. T. Van den Berg, E. J. Portier, G. Kaiser, and C. J. Van Boxtel, J. Liq. Chromatogr. Relat. Technol., 1996, 19(6), 993-1005.

21. S. Akapo, C. McCrea, J. Gupta, M. Roach, and W. Skinner, J. Pharm. Biomed. Anal., 2009, 49(3), 632-637. 